\title{
Comparative Effectiveness and Safety of Empiric Ampicillin plus Gentamicin or Empiric Piperacillin-Tazobactam in the Neonatal Intensive Care Unit
}

Irina Smith, M.D., Carolyn R. Ahlers-Schmidt, Ph.D., Barry T. Bloom, M.D. The University of Kansas School of Medicine-Wichita

Department of Pediatrics

\begin{abstract}
Background. This study was designed to assess piperacillin tazobactam (PT) as an alternative to ampicillin and gentamicin (AG) in neonates with suspected systemic infection.
\end{abstract}

Methods. A retrospective, unmatched population of AG (2007-2009) and PT (20092012) exposed infants were evaluated for initial effectiveness, adverse events, and subsequent morbidities or mortality. Data included gestational age, birth weight, sex, Apgar score, length of hospital stay, glomerular filtration rate for days 1 and 2, duration on mechanical ventilation, duration on oxygen therapy, incidence of sepsis (blood or cerebrospinal fluid culture positive), incidence of ventilator associated pneumonia, and incidence of necrotizing enterocolitis. All positive blood cultures during the study period were reviewed. Data about specific microorganisms and sensitivity to antibiotics were collected.

Results. No significant differences in demographics or initial Apgar scores were noted. There were no significant differences in systemic rash or diaper rash. PT was associated with higher glomerular filtration rate on day two. Four infants had early onset sepsis with ampicillin resistant E. coli. One of these, in the PT group, had intermediate sensitivity to gentamicin as well.

Conclusion. Use of PT as the initial empiric antibiotic was not associated with increased adverse outcomes. The challenge of ampicillin resistant Escherichia coli should encourage others to consider this change.

KS J Med 2015; 8(2):80-83.

\section{Introduction}

The most common antibiotic combination used for therapy of presumed early-onset neonatal sepsis is ampicillin and gentamicin (AG), based upon the rationale that the majority of bacterial pathogens are sensitive to this combination. The most prevalent gram positive organism is Group B Streptococcus, although this organism has been in decline coinciding with increased intrapartum ampicillin. ${ }^{1-4}$ The most frequent gram negative bacteria are Escherichia coli, followed by
Haemophilus influenza and Citrobacter species.

There are many concerns regarding the use of AG. The recommended dose is potentially insufficient to treat Listeria meningitis. ${ }^{5,6}$ Antenatal exposure and prolonged postnatal ampicillin exposure increase the risk of necrotizing enterocolitis (NEC). ${ }^{1-4,7-9}$ In addition, ampicillin increases bleeding times through a direct effect on platelets. ${ }^{1}$ However, the most important concerns are ototoxic and renal toxic effects of gentamicin, gentamicin resistance in late 
onset infection and emergence of ampicillin and gentamicin resistant $E$. coli. Given the lack of controlled experiences, the use of PT in infants less than two months is not included in the package insert.

Due to these concerns, our institution changed from AG to piperacillintazobactam (PT) for routine empiric coverage of suspected early onset of sepsis. The impact of PT was monitored in our very low birth weight (VLBW) infants. Results showed no increase in major morbidities or significant adverse events. PT was associated with a transient increase in glomerular filtration rate during exposure and decreases in NEC and diaper rash when compared with AG. ${ }^{1}$ Therefore, a study was designed to assess whether PT was associated with altered outcomes in infants with greater than 1500 grams birth weight.

\section{Methods}

A retrospective unmatched, cohort study was conducted to compare effectiveness and safety following the change from AG to PT at the Wesley Medical Center (WMC) Neonatal Intensive Care Unit (NICU). WMC switched from AG to PT in January 2010.

An unmatched comparison of AG exposed infants with PT exposed infants was conducted in the populations from two years prior (2007-2009) and three years after (2009-2012) the change in antibiotic policy. Cohorts were evaluated for effectiveness, congenital infection, adverse events, subsequent morbidities and mortality. During these two periods, there were no changes in the indications for initiation of antibiotic coverage.

Data were collected from inborn infants with the birth weight greater than 1500 grams, who had suspected systemic infection and were receiving AG $(12 / 20 / 2007-12 / 31 / 2009)$ or PT (12/20/2009-12/31/2012). Patients with Methacillin Resistant Staphylococcus Aureus colonization were excluded from the study.

Study data included gestational age, birth weight, sex, Apgar score, length of hospital stay, glomerular filtration rate (GFR) for days 1 and 2, duration on mechanical ventilation, duration on oxygen therapy, incidence of sepsis (blood or cerebrospinal fluid culture positive), incidence of ventilator associated pneumonia (clinical and radiographical change), and incidence of NEC (clinical and radiographic changes). All positive blood cultures in the study period were reviewed. Data about specific microorganisms and sensitivity to antibiotics were reviewed and collected.

Statistical methods included MannWhitney U-test, t-test and analysis of variance (ANOVA) for nominal and continuous variables. Chi-square analysis was used for categorical variables. Descriptive statistics were stratified by group.

\section{Results}

A total of 1682 patients were identified, 653 exposed to AG and 1029 exposed to PT. No significant differences in demographics or initial Apgar scores were noted (Table 1). There were no significant differences in systemic or diaper rash. PT was associated with higher GFR on day 2. Four infants had early onset sepsis with ampicillin resistant E. coli (3AG/1PT). One of these, in the PT group, had intermediate sensitivity to gentamicin as well. One additional PT infant had Haemophilus influenzae sepsis at birth which was sensitive to ampicillin. 
Table 1. Demographics and Apgar Scores

\begin{tabular}{|c|c|c|c|}
\hline Variable & AG & PT & $\begin{array}{c}\text { Test } \\
\text { Statistic }\end{array}$ \\
\hline $\mathbf{N}$ & 653 & 1029 & \\
\hline $\begin{array}{l}\text { Birth Weight - } \\
25^{\text {th }}, 50^{\text {th }}, 75^{\text {th }} \text { percentile }\end{array}$ & $1.88,2.20,2.70$ & $1.93,2.24,2.72$ & $\begin{array}{l}\mathrm{U}=1.29 \\
\mathrm{p}=0.20\end{array}$ \\
\hline $\begin{array}{l}\text { Gestational Age - } \\
25^{\text {th }}, 50^{\text {th }}, 75^{\text {th }} \text { percentile }\end{array}$ & $32,34,35.5$ & $33,34,35$ & $\begin{array}{l}\mathrm{U}=1.32 \\
\mathrm{p}=0.19\end{array}$ \\
\hline Male - N (\%) & $356(55 \%)$ & $590(57 \%)$ & $\begin{array}{c}X 2(1)=1.29, \\
p=0.26\end{array}$ \\
\hline Caesarian - N (\%) & $348(53 \%)$ & $565(55 \%)$ & $\begin{array}{c}\mathrm{X} 2(1)=0.38 \\
\mathrm{p}=0.54\end{array}$ \\
\hline $\begin{array}{l}\text { Apgar }<7 \text { at } 1 \text { minute - } \\
\mathrm{N}(\%)\end{array}$ & $232(36 \%)$ & 357 (35\%) & $\begin{array}{c}X 2(1)=0.10 \\
p=0.75\end{array}$ \\
\hline $\begin{array}{l}\text { Apgar }<7 \text { at } 5 \text { minutes - } \\
N(\%)\end{array}$ & $66(10 \%)$ & $107(10 \%)$ & $\begin{array}{c}X 2(1)=0.04 \\
p=0.85\end{array}$ \\
\hline $\begin{array}{l}\text { GFR day } 1- \\
25^{\text {th }}, 50^{\text {th }}, 75^{\text {th }} \text { percentile }\end{array}$ & $13.86,16.02,18.45$ & $14.49,16.56,18.9$ & $\begin{array}{l}U=2.692 \\
p=0.007\end{array}$ \\
\hline $\begin{array}{l}\text { GFR day } 2- \\
25^{\text {th }}, 50^{\text {th }}, 75^{\text {th }} \text { percentile }\end{array}$ & $11.34,13.55,15.48$ & $12.57,15.12,17.82$ & $\begin{array}{l}\mathrm{U}=6.612 \\
\mathrm{p}<0.001\end{array}$ \\
\hline Mortality - N (\%) & $7(1 \%)$ & $12(1 \%)$ & $\begin{array}{c}\mathrm{X} 2(1)=0.03 \\
\mathrm{p}=0.86\end{array}$ \\
\hline NEC - N (\%) & $4(0.6 \%)$ & $4(0.4 \%)$ & $\begin{array}{c}X 2(1)=0.42, \\
p=0.52\end{array}$ \\
\hline
\end{tabular}

\section{Discussion}

PT as an empiric choice for suspected neonatal sepsis was not associated with any adverse outcome and can be used successfully as a monotherapy. Patients receiving AG had a lower GFR, consistent with our previous study in which this was transient and not sustained. ${ }^{1}$ We did not abstract GFR beyond the exposure period. There are some limitations to this study. It is a retrospective, unmatched comparison study, and as such cannot be used to assert causation. However, in our previous study, ${ }^{1}$ matching did not alter

\section{References}

${ }^{1}$ Chong E, Reynolds J, Shaw J, et al. Results of a two-center, before and after study of piperacillin-tazobactam versus ampicillin and gentamicin as results; therefore, we determined it was necessary for the present study. The current challenge of ampicillin resistant $E$. coli should encourage others to consider this change.

\section{Acknowledgments}

The Wichita Medical Research and Education Foundation funded and its IRB approved this project. We appreciate the contributions of Jared Shaw, Paula Delmore, Joy Nimeskern as well as the staff of the NICU and Administration at Wesley Medical Center.

empiric therapy for suspected sepsis at birth in neonates $\leq 1500$ g. J Perinatol 2013; 33(7):529-532. PMID: 23328923. 
2 Stoll BJ, Hansen N, Fanaroff AA, et al. Changes in pathogens causing earlyonset sepsis in very-low-birth-weight infants. N Engl J Med 2002; 347(4):240-247. PMID: 12140299.

3 Bizzarro MJ, Dembry LM, Baltimore RS, Gallagher PG. Changing patterns in neonatal Escherichia coli sepsis and ampicillin resistance in the era of intrapartum antibiotic prophylaxis. Pediatrics 2008; 121(4):689-696. PMID: 18381532.

${ }^{4}$ Puopolo KM, Eichenwald EC. No change in the incidence of ampicillinresistant, neonatal, early-onset sepsis over 18 years. Pediatrics 2010; 125(5):e1031-e1038. PMID: 20385650.

${ }^{5}$ Marget W, Seeliger HP. Listeria monocytogenes infections-therapeutic possibilities and problems. Infection 1988; 16:S175-S177. PMID: 3047067.

${ }^{6}$ Hof H. An update on the medical management of listeriosis. Expert Opin Pharmacother 2004; 5(8):1727-1735. PMID: 15264987.

${ }^{7}$ Cotten CM, Taylor S, Stoll B, et al. Prolonged duration of initial empirical antibiotic treatment is associated with increased rates of necrotizing enterocolitis and death for extremely low birth weight infants. Pediatrics 2009; 123(1):58-66. PMID: 19117861.

8 Alexander VN, Northrup V, Bizzarro MJ. Antibiotic exposure in the newborn intensive care unit and the risk of necrotizing enterocolitis. J Pediatr 2011; 159(3): 392-397. PMID: 21489560.

${ }^{9}$ Weintraub AS, Ferrara L, Deluca L, et al. Antenatal antibiotic exposure in preterm infants with necrotizing enterocolitis. J Perinatol 2012; 32(9):705-709. PMID: 22157626.

${ }^{10}$ Sheffield MJ, Lambert DK, Baer VL, et al. Effect of ampicillin on bleeding time in very low birth-weight neonates during the first week after birth. J Perinatol 2011; 31(7):477-480. PMID: 21372796.

${ }^{11}$ Sheffield MJ, Lambert DK, Henry E, Christensen RD. Effect of ampicillin on the bleeding time of neonatal intensive care unit patients. J Perinatol 2010; 30(8): 527-530. PMID: 20043011.

${ }^{12}$ Ealy M, Lynch KA, Meyer NC, Smith RJ. The prevalence of mitochondrial mutations associated with aminoglycoside-induced sensorineural hearing loss in an NICU population. Laryngoscope 2011; 121(6):11841186. PMID: 21495045.

Keywords: neonatology, sepsis, antibacterial agents, ampicillin, piperacillin 